\title{
PENGARUH KARAKTERISTIK INDIVIDU, BUDAYA ORGANISASI, DAN KOMITMEN ORGANISASI TERHADAP KINERJA KARYAWAN DENGAN MOTIVASI SEBAGAI VARIABEL MODERASI (STUDI PADA KARYAWAN INSTALASI RAWAT JALAN RSUD DR. SAIFUL ANWAR MALANG)
}

\author{
Susi Susanti \\ Fakultas Ekonomi dan Bisnis Universitas Muhammadiyah Malang \\ E-mail: dea.datu.ucik9@gmail.com.
}

\begin{abstract}
This study aimed to examine the effect of the relationship of individual characteristics, organizational culture, and organizational commitment to employee performance and motivation as a moderating variable in the study of plant employees outpatient Hospital Dr. Saiful Anwar Malang. Poor This research is explanatory. Samples in this study used a sample of 113 respondents 84 employees who work on installation of outpatient Hospital Dr. Results of analysis Partial Least Square (PLS) This study shows that the individual character relationships, organizational culture, different organizational commitment remains significant positive effect on employee performance, motivation to strengthen the relationship between individual characteristics, organizational culture, and organizational commitment to employee performance.
\end{abstract}

Keywords: individual characteristics, organizational culture, organizational commitment, motivation, employee performance.

\begin{abstract}
Abstrak
Penelitian ini bertujuan untuk menguji pengaruh hubungan karakteristik individu, budaya organisasi, dan komitmen organisasi terhadap kinerja karyawan dengan motivasi sebagai variabel moderasi studi pada karyawan instalasi rawat jalan RSUD Dr. Saiful Anwar Malang. Malang. Penelitian ini bersifat eksplanatori. Sampel pada penelitian ini menggunakan sampel sebanyak 84 dari 113 responden karyawan yang bekerja pada instalasi rawat jalan RSUD Dr. Hasil analisis Partial Least Square (PLS) penelitian ini menunjukkan bahwa hubungan karakter individu, budaya organisasi, berbeda dengan komitmen organisasi berpengaruh positif dan signifikan terhadap kinerja karyawan, motivasi memperkuat hubungan antara karakteristik individu, budaya organisasi, dan komitmen organisasi terhadap kinerja karyawan.
\end{abstract}

Kata kunci: karakteristik individu, budaya organisasi, komitmen organisasi, motivasi, kinerja karyawan 
Karyawan atau pegawai merupakan unsur terpenting dalam menentukan maju mundurnya suatu perushaan. Untuk mencapai tujuan perusahaan diperlukan karyawan yang sesuai dengan persayaratan dalam perusahaan, dan juga harus mampu menjalankan tugas-tugas yang telah ditentukan oleh perusahaan. Setiap perusahaan akan selalu berusaha untuk meningkatkan kinerja karyawan, dengan harapan bahwa apa yang menjadi tujuan perusahaan akan

tercapai. Kemampuan karyawan tercermin dari kinerja, kinerja yang baik adalah kinerja yang optimal. Kinerja karyawan tersebut merupakan salah satu modal bagi perusahaan untuk mencapai tujuannnya. Sehingga kinerja karyawan adalah hal yang patut diperhatikan oleh pemimpin perusahaan (Lomanjaya, 2012).

Kinerja pada umumnya diartikan sebagai kesuksesan seseorang dalam melaksanakan suatu pekerjaan. Kinerja karyawan merupakan hasil kerja yang dicapai seseorang dalam melaksanakan tugas-tugas yang dibebankan kepadanya untuk mencapai target kerja. Kinerja karyawan merupakan salah satu faktor penentu keberhasilan perusahaan atau organisasi dalam mencapainya (Lomanjaya, 2012).

Karakteristik individu yang dimiliki seseorang, unik atau berbeda satu dengan yang lainnya. Menurut Robbins (2008), bahwa variabel ditingkat individu meliputi karakteristik biografis, kemampuan, kepribadian, proses belajar, persepsi, sikap dan kepuasan kerja. Perbedaanperbedaan tersebut dibawa kedunia kerja, sehingga motivasi setiap individu berbeda-beda.

Arba'atun (2012) dan Yunnus (2010), mengemukakan bahwa budaya organisasi yang efektif dapat memberi pengaruh positif terhadap kinerja

karyawan. Hasil penelitian yang

dilakukan oleh Brahmansari dan

Suprayetno (2008), mengatakan bahwa yang mempengaruhi kinerja karyawan adalah motivasi dan budaya organisasi Sardjito dan Muthaher (2007), Komitmen organisasi juga dapat mempengaruhi kinerja karyawan. Komitmen organisasi merupakan suatu dorongan dari dalam diri individu untuk berbuat sesuatu agar dapat menunjang keberhasilan organsasi sesuai dengan tujuan dan lebih mengutamakan kepentingan organisasi (Rudhianto, 2010), kemudian menurut Yunnus (2010) kinerja karyawan dipengaruhi oleh karakteristik individu, dan budaya organisasi.

Siagian (2007), menyatakan bahwa motivasi merupakan akibat dari interaksi seseorang dengan situasi tertentu yang dihadapinya. Karena itulah terdapat perbedaan dalam kekuatan motivasi yang ditunjukkan oleh seseorang dalam menghadapi situasi tertentu dibandingkan dengan orang-orang lain yang menghadapi situasi tertentu dibandingkan dengan orang-orang lain yang menghadapi situasi yang sama.Fenomena yang terjadi adalah masalah internal yang menciptakan lingkungan kerja yang tidak sehat yang akan berakibat menurunnya kinerja pada karyawan tersebut. Penelitian ini bertujuan untuk menguji model hubungan antara

karakteristik individu, budaya organisasi, komitmen organisasi terhadap kinerja karyawan dengan motivasi sebagai variabel moderasi.

\section{Metode Penelitian}

Metode penelitian ini akan digunakan untuk menjawab hipotesis penelitian sebagai berikut: 


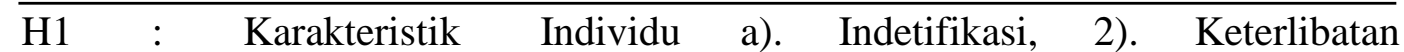
berpengaruh positif terhadap kinerja karyawan

(Gibson, 2009)

H2 : Budaya Organisasi berpengaruh positif terhadap kinerja karyawan

H3 : Komitmen Organisasi berpengaruh positif terhadap kinerja kryawan.

H4 : Motivasi memperkuat pengaruh karakteristik Individu terhadap kinerja karyawan.

H5 : Motivasi memperkuat pengaruh budaya organisasi terhadap kinerja karyawan.

H6 : Motivasi memperkuat pengaruh komitmen organisasi terhadap kinerja karyawan.

Penelitian ini menggunakan jenis eksplanatori yang mendasarkan pada teori atau hipotesis untuk menguji

suatu fenomena (Cooper,2003). Populasi dalam penelitian ini sebanyak 84 dari 113 responden karyawan yang bekerja pada instalasi rawat jalan RSUD Dr. Penelitian ini menggunakan teknik pengambilan data dengan

menyebarkan kuisioner secara langsung kepada responden. Daftar pertanyaan terkait dengan item-item variabel karakter individu, budaya organisasi, dan komitmen organisasi terhadap kinerja karyawan dengan motivasi sebagai variabel moderasi

Adapun yang menjadi indikator dalam penelitian ini adalah:

1. Karakteristik Individu (X1)

a). Kemampuan, b). Pengalaman, c). Usia (Gibson, 2000)

2. Budaya Organisasi

a). Inovatif, b) Perhatian terhadap detail, c). Orientasi terhadap hasil, d). Orientasi terhadap tim, e). Keagresifan, f). Stabilitas (Robbins, 2008)

3. Komitmen Organisasi

4. Motivasi

a). Tantangan, b). Tanggung jawab, c). Pengembangan, d). Keterlibatan, e). Kesempatan (Siswanto, 2010)

5. Kinerja Karyawan

a). Kualitas pekerjaan, b). Kuantitas pekerjaan, c). Ketepatan waktu, d). Tanggung jawab (alma, 2009)

\section{Hasil Penelitian dan Pembahasan}

Hasil olah data dengan

menggunakan alat bantu software SmartPLS, diperoleh hasil output dari model struktur konstruk loading factor yang akan menjelaskan antara konstruk hubungan karakteristik individu, budaya organisasi, komitmen organisasi, motivasi dan kinerja karyawan yang tampak pada gambar 1 . Selanjutnya, Dari tabel 2 evaluasi model pengukuran AVE pengolahan data menunjukkan nilai AVE pada setiap variabel diatas 0,5 . Berdasarkan tabel 4.13 tampak nilai AVE pada variabel Karakteristik Individu sebesar 0,607, Budaya Organisasi sebesar 0,506, Komitmen Organisasi sebesar 0,697 , Kinerja Karyawan sebesar 0,525 dan Motivasi sebesar 0,611. Dapat dikatakan bahwa secara

disciminant validity, model pengukuran tersebut adalah baik.

Pada tabel 2 koefisien determinasi (R-Square) yang didapatkan dari model variabel Karakter Individu terhadap Kinerja Karyawan sebesar 0,362 menyatakan bahwa Kinerja Karyawan mampu dijelaskan oleh variabel Karakter

Individu, Budaya Organisasi, Komitmen Organisasi, dan Motivasi sebesar 36,2\% dan sisanya sebesar $63,8 \%$ dijelaskan oleh variabel lain di luar penelitian. Dalam penelitian ini, 
Gambar 1. Full Model Penelitian

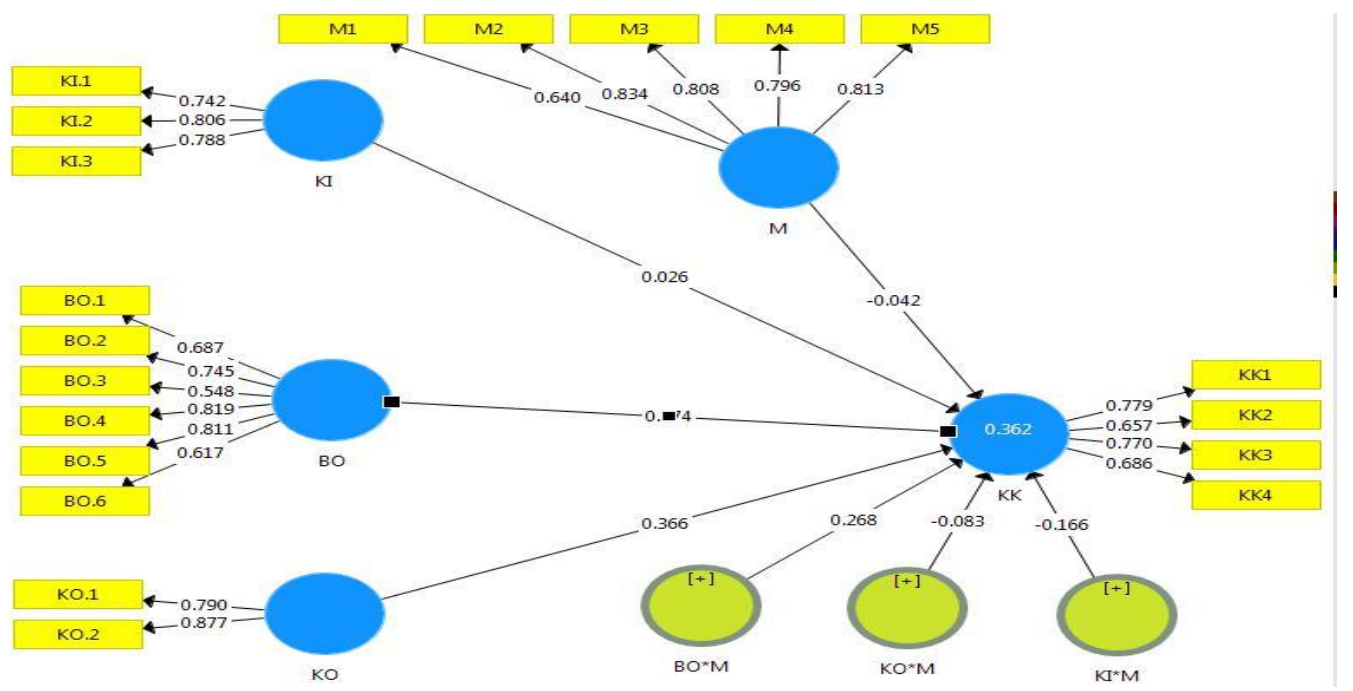

Tabel. 1 Hasil Uji Validitas dan Reabilitas

\begin{tabular}{|c|c|c|c|c|}
\hline Variabel & Indikator & Uji T & Keterangan & Reliabilitas \\
\hline Karakter & Kemampuan & 0,742 & Valid & \multirow{3}{*}{0,822} \\
\hline \multirow[t]{2}{*}{ individu } & Pengalaman & 0,806 & Valid & \\
\hline & Usia & 0.788 & Valid & \\
\hline \multirow{6}{*}{$\begin{array}{l}\text { Budaya } \\
\text { organisasi }\end{array}$} & Inovatif & 0,687 & Valid & \multirow{6}{*}{0,858} \\
\hline & $\begin{array}{l}\text { Perhatian } \\
\text { terhadap detail }\end{array}$ & 0,745 & Valid & \\
\hline & $\begin{array}{l}\text { Orientasi } \\
\text { terhadap detail }\end{array}$ & 0,548 & Valid & \\
\hline & $\begin{array}{l}\text { Orientasi } \\
\text { terhadap tim }\end{array}$ & 0,819 & Valid & \\
\hline & Keagresifan & 0.811 & Valid & \\
\hline & Stabilitas & 0.617 & Valid & \\
\hline \multirow{7}{*}{$\begin{array}{l}\text { Komitmen } \\
\text { organisasi } \\
\text { Motivasi }\end{array}$} & Identifikasi & 0,790 & Valid & \multirow{3}{*}{0,821} \\
\hline & Keterlibatan & 0,877 & Valid & \\
\hline & Tantangan & 0,640 & Valid & \\
\hline & $\begin{array}{l}\text { Tanggung } \\
\text { jawab }\end{array}$ & 0,834 & Valid & \multirow{4}{*}{0,886} \\
\hline & Pengembangan & 0,808 & Valid & \\
\hline & Keterlibatan & 0,796 & Valid & \\
\hline & Kesempatan & 0,813 & Valid & \\
\hline \multirow[t]{4}{*}{$\begin{array}{l}\text { Kinerja } \\
\text { Karyawan }\end{array}$} & $\begin{array}{l}\text { Kualitas } \\
\text { pekerjaan }\end{array}$ & 0,779 & Valid & \multirow{4}{*}{0,815} \\
\hline & $\begin{array}{l}\text { Kuantitas } \\
\text { pekerjaan }\end{array}$ & 0,657 & Valid & \\
\hline & $\begin{array}{l}\text { Ketepatan } \\
\text { waktu }\end{array}$ & 0.770 & Valid & \\
\hline & $\begin{array}{l}\text { Tanggung } \\
\text { jawab }\end{array}$ & 0,868 & Valid & \\
\hline
\end{tabular}




\begin{tabular}{ll}
\hline Tabel.2 Hasil Average Varience Extracted $(A V E)$ & \\
\hline Variabel & AVE \\
\hline Karakter individu (X1) & 0,607 \\
Budaya Organisasi (X2) & 0,506 \\
Komitmen Organisasi (X3) & 0,697 \\
Motivasi (X4) & 0,611 \\
Kinerja Karyawan (Y) & 0,525 \\
\hline
\end{tabular}

Sumber: data primer, diolah tahun 201

Tabel.3 Hasil R-Square

\begin{tabular}{|c|c|}
\hline Pengaruh & R-Square \\
\hline $\begin{array}{l}\text { Karakter individu, budaya organisasi, } \\
\text { motivasi }\end{array}$ & 0,362 \\
\hline
\end{tabular}

Sumber: data primer, diolah tahun 2016

model struktural yang digunakan tergolong moderat.

Dari tabel. 4 dapat dilihat terdapat hubungan yang positif dengan koefisien parameter $(0,026)$ dan tidak signifikan antara Karakter Individu (X1) terhadap Kinerja Karyawan (Y) karena memiliki nilai $\mathrm{t}-$ statistik sebesar $(0,183)$ lebih kecil dari nilai $\mathrm{t}$ tabel $(1,96)$, hal ini sejalan dengan Penelitian Romel (2012) yang membuktikan bahwa karakteristik individu berpangaruh positif terhadap kinerja karyawan. Selanjutnya pada hipotesis 2 terdapat hubungan yang positif antara Budaya Organisasi (X2) terhadap Kinerja Karyawan dengan koefisien parameter $(0,145)$ sejalan dengan penelitian Arba'atun (2012) dan Yunnus (2010), menyatakan bahwa Budaya Organisasi berpengaruh positif terhadap Kinerja Karyawan. Pada hipotesis ketiga terdapat hubungan yang positif dan signifikan antara komitemen Organisasi (X3) terhadap Kinerja Karyawan dengan koefisien parameter $(2,232)$ sejalan dengan penelitian Yeh dan Hong (2012) bahwa komitmen orgnaisasi berpengaruh positif terhadap kinerja karyawan. Selanjutnya pada hipotesis 4 terdapat pengaruh motivasi memperkuat pengaruh karakteristik individu terhadap Kinerja Karyawan dengan koefisien parameter $(0,989)$ sejalan dengan penelitian Robbins (2008), bahwa motivasi dapat memperkuat karakteristik individu terhadap kinerja karyawan.

Pada hipotesis 5 terdapat pengaruh motivasi memperkuat pengaruh budaya organisasi terhadap Kinerja Karyawan dengan koefisien parameter (1,375) sejalan dengan penelitian Brahmansari (2008), bahwa motivasi dapat memperkuat pengaruh budaya organisasi terhadap kinerja karyawan. Selanjutnya pada hipotesis 6 terdapat pengaruh motivasi memperkuat pengaruh komoitmen organisasi terhadap Kinerja Karyawan dengan koefisien parameter $(0,504)$ sejalan dengan penelitian Rizal dkk (2014), bahwa motivasi dapat memperkuat komitmen organisasi terhadap kinerja karyawan.

\section{Penutup}

Berdasarkan hasil penelitian tersebut, maka dapat disimpulkan sebagai berikut: Pertama, Kinerja Karyawan pada IRJ RSUD Saiful Anwar secara keseluruhan baik. Hasil kerja secara kualitas dan kuantitas 
yang dicapai oleh seorang karyawan dalam melaksanakan tugasnya sesuai dengan tanggung jawab yang diberikan kepadanya. Kinerja Karyawan merupakan hasil kerja (output) yang dihasilkan karyawan secara kualitas, kuantitas yang dicapai pada waktu

yang telah ditentukan dalam melaksanakan tugas sesuai dengan tanggung jawab yang diberikan. Hasil kinerja karyawan mampu bertanggung jawab terhadap hasil pekerjaan yang telah ditentukan dan karyawan mampu menyelesaikan pekerjaan dan tepat waktu.

Motivasi karyawan pada IRJ RSUD Saiful Anwar secara keseluruhan baik. Motivasi merupakan hal atau sesuatu yang mendorong seseorang berbuat sesuatu. Pada penelitian ini yang perlu dipertahankan oleh karyawan untuk meningkatkan motivasi adalah keterlibatan karyawan dalam kegiatan-kegiatan yang dilakukan untuk meningkatkan kemauan/keinginan dalam bekerja.

Karakteristik individu pada karyawan IRJ RSUD Saiful Anwar secara keseluruhan baik. Karakteristik individu merupakan sikap atau perilaku seseorang dalam menjalankan tugas yang diberikan dimana sikap dan perilaku tersebut berpengaruh terhadap kinerjanya. Dalam penelitian ini yang perlu dipertahankan adalah kemampuan intelektual karyawan karena mampu memudahkan karyawan dalam bekerja, sedangkan yang perlu ditingkatkan adalah umur yang memadai karena dengan umur yang produktif akan meningkatkan kinerja karyawan.

Budaya Organisasi pada karyawan IRJ RSUD Saiful Anwar secara keseluruhan baik. Budaya organisasi adalah suatu sistem nilai, norma-norma, atau aturan, falsafah, kepercayaan dan sikap (perilaku) yang dianut bersama anggota (karyawan) yang berpengaruh terhadap pola kerja serta pola manajemen organisasi. Pada penelitian ini yang perlu dipertahankan yakni karyawan karyuawasn tidak boleh melakukan kecurangan dalam menyelesaikan tugas. Sedangkan yang perlu ditingkatkan dalam budaya organisasi adalah pemberian bonus terhadap karyawan.

Komitmen Organisasi pada karyawan IRJ RSUD Saiful Anwar secara keseluruhan baik. Komitmen Organisasi merupakan perjanjian atau keterikatan untuk melakukan sesuatu (kontrak), sedangkan janji adalah perkataan yang menyatakan kesediaan dan kesanggupan untuk berbuat. Pada penelitian ini yang perlu dipertahankan dalam komitmen organisasi adalah karyawan selalu bersungguh-sungguh dan bertanggung jawab dalam setiap tugas yang diberikan oleh pimpinan. Sedangkan yang perlu ditingkatkan dalam komitmen organisasi adalah kecocokan antara nilai-nilai yang saya pegang dengan nilai-nilai yang ada dalam organisasi.

\section{DAFTAR PUSTAKA}

Ahmad, Shakil Muhammad, dan Masood, Muhammad Tahir (2011). Work family conflict

among Woman University Teachers online European Journal of Social Sciences. Vol. 23

Alma, Buchari. (2009). Kewirausahaan. Bandung: Alfabeta.

Allen, NJ., Meyer PJ. And Smith CA. (1997). Commitment to Organizations and Occupations: Extension and test of a Three- 


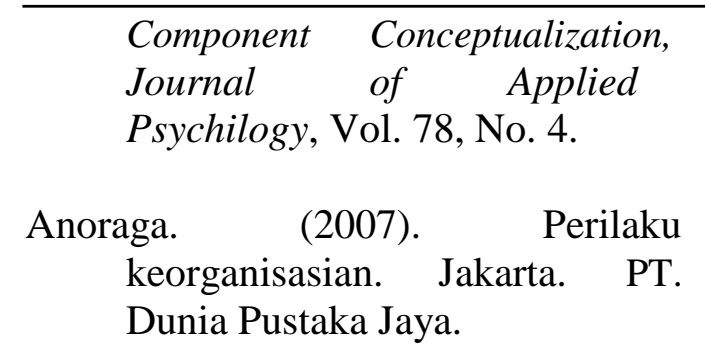

Arba'atun, Yuni. (2012). Pengaruh Gaya Kepemimpinan, Budaya Organisasi dan Motivasi Kerja terhadap Kinerja Karyawan di Dinas Pertanian Kabupaten Bojonegoro. Tesis S-2 Magister Manajemen program Pascasarjana universitas Muhammadiyah Malang.

Azis, Jakfar, (2014). Influence of Individual Characteristics, Organizational Culture and Work Motivation to Satisfaction and Performance of Hand-Rolled Cigarette Workers at the Cigarette Industry in Madura. International Journal of Science and Research (IJSR): 2319-7064.

Bedjo Siswanto (2010). Manajemen Kerja Indonesia ( Pendidikan administrasi dan operatif) Jakarta:Bumi Aksara.

Benkhoff, B. (1997). Ignoring Commitment Is Costly: New Approaches Establish The Missing Link Between Commitment And Performance. Human Relations, 50(6): 701726.

Brahmasari, Ida Ayu dan Suprayetno, Agus. (2008). Pengaruh Motivasi Kerja Kepemimpinan dan Budaya Organisasi terhadap

Kepuasan Kerja serta Dampaknya Pada Kienrja Perusahaan (study kasus pada
PT. Hei International Wirata Indonesia).

Cooper dan Schindler. (2006). Metode Riset Bisnis (Budijanto, D. Djunaedi, D. Sihombing \& Penerjemah, Trans. 9 ed.). PT Media Global Edukasi. Jakarta.

Darsana, Made .(2013). The Influence of Personality And Organizational Culture On Employee Performance Through Organizational Citizenship Behavior.

Darwinto (2008). Analisis Pengaruh Gaya Kepemimpinan terhadap Kepuasan Kerja dan Komitmen Organisasi untuk meningkatkan Kinerja Karyawan (Studi pada RSUD Kota Semarang), Tesis S2 Magister Manajemen dipublikasikan, Universitas Diponegoro Semarang.

Davis, Keith dan John W. Newstrom. (2000). Perilaku dalam Organisasi. Edisi Ketujuh, Alih Bahasa Agus Darma. Erlangga. Jakarta.

Darmawan, D. (2013). Metode Penelitian Kuantitatif. PT Remaja Rosdakarya. Bandung.

Ghazali, I. (2013). Model Persamaan Struktural Konsep Dan Aplikasi Dengan Program AMOS 21.0 (Edisi ketujuh ed.).BP Undip. Semarang.

Gibson. (2000). JR Organization. Mc Graw-hill.

Handoko, T. Tani. (1991). Manajemen Personalia dan Sumber Daya 
Manusia edisi dua. BPFE. Yogyakarta.

Heryanti, Dewinta. (2007). Pengaruh Budaya Organisasi, Kepuasan Kerja, dan Gaya Kepemimpinan terhadap Kinerja Pegawai melalui Komitmen Organisasi Sebagai Variabel Intervening (study pada PT. PLN Persero apj Semaranf). Tesis $\quad S-2$ Dipublikasikn, Universitas Diponegoro Semarang).

Hasibuan, Malayu SP. (2011). Manajemen Sumber Daya Manusia. Edisi Kelimabelas. Jakarta: PT Bumi Aksara.

Ivancevich, John M, Konopaske Robert dan Mattenson, Michael T. (2006). Perilaku-perilaku dan Mnajemen Organisasi. Erlangga.

Jack Henry Syauta, Eka Afnan Troena, Margono Setiawan, Solimun. (2012). The Influence of Organizational Culture, Organizational Commitment to Job Satisfaction and Employee Performance (Study at Municipal Waterworks of Jayapura, Papua Indonesia, Volume IIssue 1 :6976.

Jayusman, Hendra, dan Khotimah, Siti (2012). Pengaruh Kepemimpinan, Komunikasi, Motivasi, Pengembangan Karir dan Promosi Jabatan terhadap Kinerja Pegawai kantor Setda Kabupaten Kota Waringin Barat. Jurnal SPEAD, Vol. 7, No.2, 171-188.

Koesmono, H, Temon. (2005). Pengaruh Budaya Organisasi Terhadap Motivasi dan
Kepuasan Kerja Serta Kinerja Karyawan Pada sub sektor Industry Pengolahan Kayu Skala Menengah di Jawa Timur, jurnal manajemen dan kewirausahaan, vol. 7, no. 2, 171-180.

Lomanjaya, J., M. Laudi, D. C. Widjaja, dan E.W. Kartika .(2012). Analisis Pengaruh Gaya Kepemimpinan Transformasional Dan Transaksional Terhadap Kinerja Karyawan PT. ISS Indonesia Cabang Surabaya di RS. Katolik ST Vincentius A. Pauolo.

Lumbanraja, Prihatin. (2009). Evaluasi Kinerja SDM. PT Refika Aditama. Bandung.

Mangkunegara, A.A dan Anwar, Prabu. (2005). Manajemen Sumber Daya Manusia. PT Remaja Doskarya. Bandung.

Mangkunegara, A. P. (2006). Manajemen Sumber Daya Manusia Perusahaan. Bandung: PT. Remaja Rosdakarya. 